\title{
Teaching Experience on Faculty Members' Perceptions about the Attributes of Open Educational Resources (OER)
}

\author{
https://doi.org/10.3991/ijet.v12i04.6638 \\ Muhua Zhang \\ China Three Gorges University, Yichang, China \\ zhangmuhua@ctgu.edu.cn \\ Yan Li \\ Zhejiang University, Hangzhou, China \\ yanli@zju.edu.cn
}

\begin{abstract}
The purpose of this study was to investigate the impact of online teaching experience on faculty members' perceptions about attributes of OER. Rogers' (2003) attributes of innovation theory was adopted as the theoretical base in this study. And questionnaire survey was carried out at Zhejiang University (ZJU) in China. 360 faculty members from ZJU were randomly invited to complete a questionnaire. The results of data analysis found that (1) only small portion of surveyed faculty members had online teaching experience while there was large portions of participants indicated that they would be willing to share their educational resources on the ZJU website or on outside websites; (2) the majority of the participants tended to agree that there is a relative advantage and compatibility of OER, though they were more neutral regarding the complexity, trialability and observability of OER; (3) online teaching experiences significantly impacted faculty members' perceived trialability and observability of OER. Based on the finding, the study suggested that universities may carry out more initiatives efforts to increase faculty members' online teaching experience and to improve faculty members' perceived attributes of OER.
\end{abstract}

Keywords-Open Educational Resources (OER), perceptions, online teaching, attributes, faculty members

\section{Introduction}

The term "Open Educational Resources" (OER) was coined and first defined during the forum on the Impact of Open Courseware for Higher Education Institutions in Developing Countries held by UNESCO [1]. OER was first defined as "the open provision of educational resources, enabled by information and communication technologies, for consultation, use and adaptation by a community of users for noncommercial purposes" on this forum [2]. According to this definition, a wide variety of 
objects and online materials which can be used freely and openly for education all belong to OER, including those materials without Creative Commons licensed.

As we all know, the worldwide OER movement was initiated by the famous Open Courseware (OCW) project launched by Massachusetts Institute of Technology (MIT). Then, more and more OER initiatives were launched around the world, such as the Open CourseWare Consortium consisted of more than 200 institutions of higher education and associated organizations from around the world, Open Learning Initiative (OLI) launched by Carnegie Mellon University [3], OpenLearn from the Open University in UK [4], and Teacher Education in Sub-Saharan Africa (TESSA) which is a research and development project working to improve the quality of university-led primary school teacher education through OER [5].

To keep up with worldwide Open Educational Resources (OER) movement in the past decades, China actively put forward its own OER projects. The influential ones include the Chinese Quality Course (CQC) Project, National Cultural Information Resources Sharing Project, and the Science Data Sharing Project. Among them, the CQC project, initiated by the Ministry of Education of the People's Republic of China, is the most influential one that has been impacting Chinese higher education reform for more than one decade. Between 2011 and 2012, Chinese Ministry of Education successively put forward "Video Open Course" (VOC) Project, which aims to improve college students' and the public's science culture quality through putting the lecture videos of professors from well-known Chinese universities online, and the "Resources-Sharing Courses" (RSC) project to further improve the opening of higher education and the sharing of quality educational resources..

\section{Literature review}

OER-related papers, books, and reports have increasingly appeared in international academia. Some studies discussed the definition and scopes of OER practice [6][7]. Some discussed the impact of OER in higher education worldwide and OER-related policy making [8][9]. Some explored the mechanics of diffusion and adoption of OER in developed countries as well as in developing countries [10][11][12]. These western literatures become important references for Chinese OER practices and studies. Currently, Chinese OER study mainly focused on the connotation of OER, the introduction and review of the foreign successful OER projects, the analysis of the construction, mechanisms for sharing, and implementation or operation of OER; and the analysis of the problems and issues related to OER development and sustainability $[13][14]$.

OER, as one of the biggest innovation happened in modern education system, is closely related to online education practice. Since OER are mainly web-based educational resources, its potential users, whatever teachers or students, need to adopt an online pedagogical method to use it. Therefore, its potential adopters' online teaching and learning experience would play an important role in adopting OER. According to Sloan Consortium's recent survey, although online education has developed for more than two decades, American faculty members' acceptance of online education was 
still in a relatively low status and the majority of surveyed American faculty members (73.6\%) had no aware of OER and Creative Commons (CCs) [15]. Considering few studies focusing on faculty members' (as OER adopters) perceptions about OER and how their online teaching experience impact their perceptions, the study aims to explore the issue in China.

\section{Theoretical base}

In describing faculty members' perceptions about OER, Rogers (2003)' attributes of innovation theory was adopted as the theoretical base in the study. According to the theory, attributes of innovation include five items, named relative advantage, compatibility, complexity, trialability, and observability. "Relative advantage" relates to the extent to which the new item or innovation is deemed an enhancement over the one that it supersedes. "Compatibility" refers to the extent to which the new item or innovation is deemed consistent with prior uses, values, experiences, and needs of potential adopters. "Complexity" is the extent to which that new item or innovation is deemed difficult to comprehend and ultimately use. "Trialability" is the degree to which a new item or innovation can be piloted or experimented with on a somewhat limited or trial basis (such as new software coming out in "beta"). "Observability" refers to the degree to which the new item or innovation can be witnessed or seen by others. According to Rogers (2003), rate of diffusion of innovation is highly related to people's perceptions of these five important attributes of innovations [16].

\section{$4 \quad$ Purpose and objectives}

The study was initiated to inquire the impact of online teaching experience on faculty members' perceptions of the key attributes of OER. This study was conducted at Zheijiang University in China during the 2014-2015 academic years. The specific objectives of the present study include (1) Describing faculty members' online teaching experience; (2) Describing faculty perceptions about attributes of OER; and(3) Examining the impact of faculty members' online teaching experience on their perceived attributes of OER.

\section{$5 \quad$ Method}

\section{$5.1 \quad$ Sample}

The target population of this study was faculty members at the Zhejiang University in China, which is a comprehensive and research-oriented university founded in 1897. ZJU is constituted by seven distinct faculties, including 20 Colleges and 113 majors. ZJU is one of the active advocates and participants of OER in Chinese higher education institutions. Since 2003, ZJU have actively participated in Chinese higher education's OER development projects, including the CQC, PQC and VOC Projects. Be- 
tween 2003 and 2010, 64 CQCs and 124 PQCs were produced by ZJU. All of these CQCs and PQCs are available on the National CQC online and the ZJU website. Since 2014, 17 MOOCs have been produced by ZJU. All these MOOCs are available on iCourse.

\subsection{Instrumentation}

Based on literature review, a three-part questionnaire was developed as the research instrument. The first part of the questionnaire aimed at gathering participants' personal characteristics, including faculty, gender, age, title, and seniority. The second part was about online teaching experience, including four aspects: (1) experience of online teaching; (2) if having experience of online teaching, manner of educational resource sharing; (3) willing to publish their educational resources on the website of their university; and (4) willingness to publish their educational resources on the website outside of their university.

Participants' perceptions about attributes of OER were measured in the third part of the survey. Rogers' (2003) attributes of innovation were used as the theoretical base. Moore and Benbasat's (1991) measurements of the main attributes of innovation were modified for this part [17]. Each attribute of OER was measured based on three statements. Participants were asked to indicate their perceptions regarding the five attributes of OER by responding to fifteen statements on a five-point Likert scale from strongly disagree to strongly agree: $1=$ strongly disagree; $3=$ neutral; and $5=$ strongly agree.

\subsection{Data Collection and Analysis}

Data were collected from September 2014 to June 2015. In total, 380 faculty members were randomly invited from ZJU to participate in the survey. All participants were provided with written information introducing the nature and purpose of the research project. At the same time, these participants were also told that they could choose not to fill in part or all of the survey and that the survey was anonymous. 360 useful surveys were returned and the response rate was about $95 \%$.

Data were compiled and analyzed using the Statistical Package for Social Sciences (SPSS19.0). Because the level of measurement for variables was interval, the final score for each attribute was computed using an unweighted factor score in the subsequent analysis. Reliability was examined using Cronbach's $\alpha$ values for each variable: Relative Advantage, 0.91; Compatibility, 0.84; Complexity, 0.92; Trialability, 0.86; Observability, 0.77 . Obviously, Cronbach's $\alpha$ values of each attribute of OER were all above 0.75 , which is a commonly acceptable level.

Descriptive statistics were used to describe each variable. Independent sample t test was used to examine the relationships between faculty members' online teaching experience and their perception about attributes of OER. Alpha for all statistical procedures was set a priori at .05 . 


\section{$6 \quad$ Findings}

Among the 360 participating faculty members, 230 (64.1\%) of them were male and $129(35.9 \%)$ were female. As to the age of the participants, $54(15 \%)$ were between 25 and 30 years old, $166(46.1 \%)$ were between 31 and 35 years old, 82(22.8\%) were between 36 and 40 years old, and 45(12.5\%) were over 41 years old. Among the participating faculty members, $49(13.8 \%)$ were professors, $164(46.3 \%)$ were associate professors, and $141(39.8 \%)$ were assistant professors.

As to the academic background of the participants, 94(26.1\%) were from the Faculty of Engineering, 54(15\%) were from the School of Medicine, 46(12.8\%) were from the Faculty of Social Sciences, 40(11.1\%) were from the Faculty of Arts and Humanities, 40(11.1\%) were from the Faculty of Agricultural, life and Environment Sciences, 38(10.6\%) were from the Faculty of Information technology, 14(3.9\%) were from the College of Science, $15(4.2 \%)$ were from the City colleges, and $16(4.4 \%)$ were from some Independent Institutes, such as China Academy of West Region Development.

\subsection{Describe faculty members' online teaching experience}

Objective one was to describe faculty members' online teaching experience. As Table 1 indicates, among the 360 participants, just $53(14.7 \%)$ had online teaching experience, while the remaining respondents 303 (84.2\%) lacked it. Among the 53 participants who had the experience of online teaching, $22(41.51 \%)$ faculty members made their materials available without any restrictions, whereas $30(56.6 \%)$ of them made their materials available with entry restrictions. The remaining faculty members did not make their materials available to others. When the participants were asked if they would be willing to publish their private educational resources on the website of their university as well as outside, $316(87.8 \%)$ respondents were quite willing to publish their private educational resources on the ZJU website. $222(61.7 \%)$ would be willing to publish their private educational resources outside the university.

\subsection{Describe faculty members' perceptions about attributes of OER}

Objective two was to describe faculty members' perceptions about attributes of OER. Table 2 shows the means and standard deviations of the five attributes. Generally speaking, participating faculty members tended to agree with the existence of relative advantage and compatibility of OER, while they tended to have more neutral attitudes toward the existence of complexity, trialability, and observability of OER.

\subsection{Examining the impact of faculty members' online teaching experiences in relation to their perceptions about attributes of OER}

Objective three was to examine the impact of faculty members' online teaching experiences in relation to their perceptions about attributes of OER. As Table 3 illustrates, online teaching experience had a significant impact both on observability and trialability attributes of OER $(\mathrm{p}<.05):(1)$ observability, t $(356)=2.48$; (2) trialability, 
$\mathrm{t}(356)=2.44$. While online teaching experience had no significant impact on the other three attributes.

Table 1. Participating ZJU faculty members' online teaching experience $(\mathrm{n}=360)$

\begin{tabular}{|l|l|c|c|}
\hline \multicolumn{1}{|c|}{ Questions } & \multicolumn{1}{c|}{ Options } & Sample & Percent (\%) \\
\hline \multirow{4}{*}{ Experience of online teaching } & Yes & 53 & 14.7 \\
\cline { 2 - 4 } & No & 303 & 84.2 \\
\cline { 2 - 4 } & Missing & 4 & 1.1 \\
\hline \multirow{2}{*}{$\begin{array}{l}\text { If having experience of online teaching, } \\
\text { which manner of educational resource shar- } \\
\text { ing }\end{array}$} & Without restriction & 22 & 41.5 \\
\cline { 2 - 4 } & With entry restriction & 30 & 56.6 \\
\cline { 2 - 4 } & Missing & 1 & 1.89 \\
\hline \multirow{2}{*}{$\begin{array}{l}\text { Willingness to publish their educational } \\
\text { resources on the website of their university }\end{array}$} & Yes & 316 & 87.8 \\
\cline { 2 - 4 } & No & 37 & 10.3 \\
\cline { 2 - 4 } & Missing & 7 & 1.9 \\
\hline \multirow{2}{*}{$\begin{array}{l}\text { Willingness to publish their educational } \\
\text { resources on the website outside of their } \\
\text { university }\end{array}$} & Yes & 222 & 61.7 \\
\cline { 2 - 4 } & No & 129 & 35.8 \\
\cline { 2 - 4 } & Missing & 9 & 2.5 \\
\hline
\end{tabular}

Table 2. Participating faculty members' perceptions about attributes of OER $(n=360)$

\begin{tabular}{|l|c|c|c|}
\hline \multicolumn{1}{|c|}{ Attributes of OER } & Sample & Mean & Standard Deviation \\
\hline Relative advantage & 360 & 4.11 & 0.59 \\
\hline Compatibility & 360 & 4.02 & 0.62 \\
\hline Complexity & 360 & 3.38 & 0.82 \\
\hline Trialability & 360 & 3.39 & 0.84 \\
\hline Observability & 360 & 3.42 & 0.70 \\
\hline Note: $1=$ Strongly Disagree (SD), 2=Disagree (D), 3=Neutral (N), 4=Agree (A), 5=Strongly Agree (SA) \\
\hline
\end{tabular}

Table 3. Distribution of participants' perception about attributes of OER by “online teaching experience" $(n=360)$

\begin{tabular}{|c|c|c|c|c|c|c|c|}
\hline Attributes of OER & $\begin{array}{c}\text { Online teaching } \\
\text { experience }\end{array}$ & $\mathbf{N}$ & $\mathbf{M}$ & SD & DF & $\mathbf{t}$ & $\mathbf{P}$ \\
\hline \multirow{2}{*}{ Relative advantage } & Have & 53 & 4.23 & 0.52 & \multirow{2}{*}{354} & \multirow{2}{*}{1.67} & \multirow{2}{*}{.10} \\
\hline & Have no & 303 & 4.09 & 0.60 & & & \\
\hline \multirow{2}{*}{ Compatibility } & Have & 53 & 4.04 & 0.54 & \multirow{2}{*}{354} & \multirow{2}{*}{0.32} & \multirow{2}{*}{.75} \\
\hline & Have no & 303 & 4.01 & 0.64 & & & \\
\hline \multirow{2}{*}{ Complexity } & Have & 53 & 3.39 & 0.81 & \multirow{2}{*}{354} & \multirow{2}{*}{0.14} & \multirow{2}{*}{.89} \\
\hline & Have no & 303 & 3.37 & 0.82 & & & \\
\hline \multirow{2}{*}{ Trialability } & Have & 53 & 3.64 & 0.70 & \multirow{2}{*}{354} & \multirow{2}{*}{$2.48^{*}$} & \multirow{2}{*}{.01} \\
\hline & Have no & 303 & 3.33 & 0.86 & & & \\
\hline \multirow{2}{*}{ Observability } & Have & 53 & 3.63 & 0.63 & \multirow{2}{*}{354} & \multirow{2}{*}{$2.44^{*}$} & \multirow{2}{*}{.02} \\
\hline & Have no & 303 & 3.38 & 0.70 & & & \\
\hline
\end{tabular}

Note: $1=$ Strongly Disagree (SD), 2=Disagree (D), 3=Neutral (N), 4=Agree (A), 5=Strongly Agree (SA);

${ }^{*}$ Correlation is significant at $\mathrm{p}<.05$. 


\section{Discussion}

The study discovered that there was only a small portion of ZJU faculty members who had online teaching experience. However, interestingly, almost $90 \%$ of the study participants indicated that they would be willing to share their educational resources on the ZJU website, while about $60 \%$ participants willing to publish their personal educational resources on outside websites. Such findings coincide with the recent study by Acker et al. (2014) which found that sharing intention is stronger in an interpersonal context (such as school-based sharing) than in a Web-based context, which is probably related with self-efficacy to share knowledge and competence-based trust [18].

As to ZJU faculty members' perceptions about OER, the majority of them tended to agree with the existence of relative advantage of OER and compatibility of OER as its attributes of innovation. However, they tended to have more neutral attitudes toward the existence of complexity, trialability, and observability of OER as its attributes of innovation. This may attributed to ZJU faculty members' lack of the experience of OER usage or development. The results of recent investigations to University of South Africa (Unisa) just confirmed this. The study found that although faculty members at Unisa had knowledge and understanding of OER, they had not actually participated in OER initiative [19]. The investigations to the Open University of Tanzania (OUT) also found that although OUT staff were willing to engage with OER, they had limited awareness, skills and competencies in the creation, integration and use of OER [20].

The result of independent sample $t$ test indicated that online teaching experiences had a significant impact both on the participants' perceived observability and trialability attribute of OER. Such findings concurred with Rogers' viewpoint that previous practice would impact one's perception about the attributes of an innovation. It also indicated that more online teaching opportunities are needed for faculty members to participate in OER-related practice in order to increase their perceived attributes of OER.

\section{Conclusion and recommendation}

In addition to much comprehensive discussion about OER at the initial stage, more and more studies began to explore the perceptions and usage of OER from different potential adopters in different countries. However, few studies focused on the impact of online teaching experience on faculty members' perceptions of OER. The current study was intended to respond to this gap in the knowledge base about the potential factors influencing perceptions on OER at one comprehensive university in China.

In this study, we attempted to explore faculty members' perceptions on OER and the impact of online teaching experience on their perceptions of the five key attributes of OER. The results indicated that although only a small portion of ZJU faculty members who had online teaching experience, most of them had strong willingness to share their personal educational resources on the web. However, the participating ZJU 
faculty members tended to agree with the existence of relative advantage and compatibility of OER, while they tended to have more neutral attitudes toward the existence of complexity, trialability, and observability of OER. Interestingly, online teaching experiences had a significant impact both on the participants' perceived observability and trialability attribute of OER.

Based on above findings, the researchers of the study recommend that more opportunities are needed for faculty members to participate in online teaching and OERrelated practices. To decrease OER's complexity and to increase OER's trialability and observability, universities should carry out more formal or informal initiatives to encourage faculty members' online activities. It is a better way to inform all faculty members by putting online teaching and OER relevant news on university websites. And, there is a great need to set up a special organization to hold more seminar, workshops or training programs at regular intervals to introduce online teaching methods and OER using skills to all faculty members. It is also very necessary to put forward more rewards and incentives related to online teaching practice and/or OER development/adoption behaviors both on national level and school level.

\section{Acknowledgment}

This work was supported by grant from the National Social Science Foundation of China (13CGL113).

\section{References}

[1] D’Antoni, S. (2009). Open educational resources: reviewing initiatives and issues, Open Learning: Journal of Open, Distance and e-Learning, 9: 3-10.

[2] UNESCO (2002). Forum on the impact of open courseware for higher education in developing countries. Final Report. UNESCO. Paris. Retrieved from http://unesdoc.unesco.org/images/0012/001285/128515e.pdf

[3] Atkins, D. E., Brown, J. S. and Hammond A. L. (2007). A review of the open educational resources (OER) movement: Achievements, challenges, and new opportunities. Retrieved from http://www.citeulike.org/user/johnroseadams/article/10295713

[4] Lane, A. (2010). Global trends in the development and use of open educational resources to reform educational practices. Retrieved from http://unesdoc.unesco.org/images/0019/001913/191362e.pdf

[5] Thakrar, J., Zinn, D. and Wolfenden, F. (2009). Harnessing open educational resources to the challenges of teacher education in sub-Saharan Africa, International Review of Research in Open \& Distance Learning, 10: 239-287. https://doi.org/10.19173/ irrodl.v10i4.705

[6] OECD (2007). Giving knowledge for free: the emergence of open education resources. Paris: OECD Publishing. Retrieved from http://www.oecd.org/edu/ceri/38654317.pdf

[7] UNESCO and COL (2011). Guidelines for open educational resources (OER) in higher education. Retrieved from http://unesdoc.unesco.org/images/0021/002136/213605e.pdf

[8] Lane, A. and McAndrew, P. (2010). Are open educational resources systematic or systemic change agents for teaching practice?" British Journal of Educational Technology, 42: 952-962. https://doi.org/10.1111/j.1467-8535.2010.01119.x 
[9] Hoosen, S. and Butcher, N. (2012). Survey on governments' open educational resources (OER) policies. Retrieved from http://www.col.org/resources/publications/Pages/detail.aspx?PID $=408$

[10] Conrad, D., Macintosh, W. and McGreal, R. et al. (2013). Report on the assessment and accreditation of learners using open education resources (OER). Retrieved from http://www.col.org/resources/publications/Pages/detail.aspx?PID=458.

[11] McGreal, R. Kinuthia, W. and Marshall, S. (2013) Open educational resources: Innovation, research and practice. Retrieved from http://www.col.org/resources/publications/Pages/detail.aspx?PID=447

[12] Wolfenden, F., Buckler, A. and Keraro, F. (2012) OER adaptation and reuse across cultural contexts in Sub Saharan Africa: Lessons from TESSA (Teacher Education in Sub Saharan Africa), Journal of Interactive Media in Education, 3:1-16.

[13] Håklev, S. (2010). The Chinese national top level courses project: Using open educational resources to promote quality in undergraduate teaching. Unpublished Master Thesis, University of Toronto, Toronto, Canada.

[14] Wang, C. Y. and Zhao, G. D. (2011) Open educational resources in the People's Republic of China: Achievements, challenges and prospects for development. Retrieved from http://iite.unesco.org/pics/publications/en/files/3214700.pdf

[15] Allen, E. and Seaman, J. (2014) Grade level: Tracking online education in the United States, Retrieved from http://onlinelearningconsortium.org/read/survey-reports-2014/

[16] Rogers, E. M. (2003). Diffusion of innovation (5th ed.). New York: The Free Press.

[17] Moore, G. C. and Benbasat, I. (1991). Development of an instrument to measure the perceptions of adopting an information technology innovation," Information Systems Research, 2:192-222. https://doi.org/10.1287/isre.2.3.192

[18] Acker, F.V., Vermeulen, M. and Kreijns, K. et al. (2014). The role of knowledge sharing self-efficacy in sharing Open Educational Resources, Computers in Human Behavior, 39: 36-144.

[19] De Hart, K., Chetty, Y. and Archer, E. (2015). Uptake of OER by staff in distance education in South Africa, International Review of Research in Open \& Distance Learning, 16:18-45. https://doi.org/10.19173/irrodl.v16i2.2047

[20] Muganda, C. K., Samzugi, A. S. and Mallinson, B. J.(2016). Analytical insights on the position, challenges, and potential for promoting OER in ODEL institutions in Africa," International Review of Research in Open \& Distance Learning, 17:37-49. https://doi.org/10.19173/irrodl.v17i4.2465

\section{Authors}

Muhua Zhang is a lecture in college of computer and information technology, China Three Gorges University, Yichang, 443002, China. Her research interests include e-learning, open and distant education and the application of ICT in education.

Yan Li is a professor of the Department of Curriculum and Learning Science, College of Education, Zhejiang University, Hangzhou, 310028, China. Her research field involving distance education, ICT education, media education, diffusion of educational innovations, and etc.

Article submitted 9 January 2017. Published as resubmitted by the authors 16 February 2017. 